\title{
Paquioniquia congénita tipo I o síndrome de Jadassohn- Lewandowsky: un caso de presentación familiar
}

\section{Congenital pachyonychia type I or Jadassohn-Lewandowsky syndrome: a familial case}

\author{
Sandra M. Cerón-Narváez', Jhon F. Cerón-Narváez², \\ Diego F. Dorado ${ }^{3}$, María A. Acosta-Aragón ${ }^{4}$
}

\begin{abstract}
Resumen. La paquioniquia congénita es una rara genodermatosis de herencia autosómica dominante, que produce alteración de la queratinización a nivel de piel, uñas y mucosas. El primer caso fue descrito por Jadassohn y Lewandowsky en 1906, y actualmente afecta a miles de personas en el mundo. El Registro Internacional de Investigación de Paquioniquia Congénita (IPCRR, del inglés, International PC Research Registry) ha identificado a nivel mundial hasta enero de 2020, 977 individuos en 517 familias con paquioniquia congénita, confirmadas genéticamente. Esta condición es considerada en nuestro país como una enfermedad huérfana, y previamente solo hay un reporte en la literatura de un caso en 2009. Se presenta el caso clínico de un paciente masculino de 23 años de edad procedente del área rural del municipio de Timbío, Colombia, con historia clínica de distrofia ungueal hipertrófica en todas las uñas de manos y pies, queratodermia palmoplantar y dolor plantar moderado a severo. Además, presentaba leucoqueratosis oral, hiperqueratosis folicular en muslos e hiperhidrosis palmoplantar. No presentaba quistes foliculares ni antecedente de dientes natales. Sus manifestaciones clínicas se catalogaron como propias de la paquioniquia congénita tipo I. Sumado a lo anterior, se identificaron características clínicas similares en otros miembros de la familia en tres generaciones, incluidos un hermano, la madre y la abuela materna, lo cual evidenció un patrón de herencia propio de esta enfermedad.
\end{abstract}

Palabras clave: paquioniquia, distrofia ungueal, queratosis, queratodermia, leucoqueratosis.

\footnotetext{
${ }^{1}$ Médica General, Facultad de Ciencias de la Salud, Universidad del Cauca. Popayán, Colombia.

${ }^{2}$ Estudiante IX Semestre de Medicina, Facultad de Ciencias de la Salud, Universidad del Cauca. Popayán, Colombia.

${ }^{3}$ Médico General, Facultad de Ciencias de la Salud, Universidad del Cauca. Popayán, Colombia.

${ }^{4}$ Médica, MSc en Biología-Genética Clínica, PhD en Genética de Poblaciones Humanas y Genética Forense. Profesora

Titular, Departamento de Pediatría, Facultad de Ciencias de la Salud, Universidad del Cauca. Popayán, Colombia. E-mail: morin1924@gmail.com.
}

Conflicto de interés: los autores declaran que no tienen conflicto de interés.

Medicina \& Laboratorio 2020;24:333-343. https://doi.org/10.36384/01232576.341

Recibido el 24 de abril de 2020; aceptado el 21 de mayo de 2020. Editora Médica Colombiana S.A., 2020. 


\begin{abstract}
Pachyonychia congenita is a rare genodermatosis of autosomal dominant inheritance pattern that affects keratinization at the level of skin, nails and mucous membranes. The first case was described by Jadassohn and Lewandowsky in 1906 and it affects thousands of people around the world. The International Pachyonychia Congenita Research Registry (IPCRR) has identified until January 2020, worldwide, 977 individuals in 517 families with pachyonychia congenita genetically confirmed. This condition is considered in our country as an orphan disease and there has only been one previous case report in 2009. We present a case of a 23-year old male patient from the rural area of Timbio, Colombia, with a history of hypertrophic nail dystrophy in all nails and toenails, palmoplantar keratoderma and moderate plantar pain. In addition, he presented oral leucokeratosis, follicular hyperkeratosis in the thighs, and palmoplantar hyperhidrosis. No follicular cysts were present nor history of natal teeth. Clinical manifestations were classified as typical of congenital pachyonychia type I. Furthermore, similar clinical manifestations were identified in other family members from three generations, including his brother, mother and maternal grandmother, a characteristic inheritance pattern of this illness.
\end{abstract}

Keywords: pachyonychia, ungueal dystrophy, keratosis, keratoderma, leukokeratosis.

\section{Introducción}

La paquioniquia congénita (PC) fue descrita por primera vez por Muller en 1904 y luego por Wilson en 1905, y su asociación con queratodermia palmoplantar y otros defectos ectodérmicos fue reportada por Jadassohn y Lewandowsky en 1906, quienes describieron a una paciente de 15 años de edad que cursaba con tuberculosis de piel y queratinización inusual de la piel y la lengua desde la infancia; sobre ella, escribieron: "Las placas ungueales de todos los dedos de las manos y los pies están extremadamente engrosadas, y tan difíciles de retirar que no se pueden cortar con unas tijeras; el padre tiene que cortarlas con un martillo y un cincel". Posteriormente, se describieron otras características adicionales como hiperhidrosis de la nariz, las palmas y las plantas, la hiperqueratosis papular de las rodillas y los codos, y la leucoqueratosis oral $[1,2]$. La comprensión genética de esta patología no se dilucidó hasta 1994, después de estudiarse la epidermólisis bullosa simplex (EBS), el primer trastorno de queratina para el que se identificaron bases moleculares. Gracias a ello, actualmente se sabe que las mutaciones en uno de cinco genes responsables de la queratina son las causantes de PC [3].

La PC es una rara genodermatosis del tipo displasia ectodérmica, con una prevalencia estimada de 0,9 por millón de individuos [4], cuyas características clínicas más destacadas son la distrofia ungueal y la disqueratosis de la piel y las mucosas. Se presenta en ambos sexos y clínicamente puede manifestarse desde el nacimiento [5]. Es transmitida como un rasgo autosómico dominante, causada por mutaciones en uno de cinco genes que codifican para la queratina: KRT6A, KRT6B, KRT6C, KRT16 y KRT17 [6]. La mayoría son mutaciones heterocigóticas con cambio de sentido o pequeñas inserciones o deleciones. Estos genes se expresan en el lecho ungueal, epidermis palmoplantar, mucosa oral y laríngea, dientes y cabello, y son respon- 
sables de producir queratinas, las cuales son proteínas que conforman filamentos fibrosos y resistentes que ayudan a las células a manejar la presión y el estiramiento, desempeñando un papel clave en su integridad y resistencia mecánica. En la PC los filamentos no se forman correctamente, lo que causa una fragilidad celular extrema, y por ende, fragilidad del citoesqueleto de las células epiteliales que lleva a citólisis celular, formación de ampollas e hiperqueratosis compensatoria [7-11].

Este raro desorden genético afecta a miles de personas en el mundo, y la rareza de su presentación dificulta la evaluación precisa de su prevalencia. El Registro Internacional de Investigación de Paquioniquia Congénita (IPCRR, del inglés, International PC Research Registry) ha identificado hasta el momento, a nivel mundial, 977 individuos con PC confirmada genéticamente [6]. Esta condición es considerada en nuestro país como una enfermedad huérfana según la resolución 2048 del 9 junio del 2015. En Colombia solo hay en la literatura un reporte de caso clínico de esta patología, publicado en el año 2009 en la revista de la Asociación Colombiana de Dermatología, el cual trata de un paciente de 8 años con características clínicas concordantes con paquioniquia congénita tipo I [12].
Esta enfermedad debe ser sospechada en las personas que presenten las características clínicas enunciadas en la tabla 1 y/o si hay hallazgos clínicos en la historia familiar de un patrón de herencia autosómico dominante. La ausencia o presencia de ciertas características, así como la edad de inicio, varían según el gen mutado. También la gravedad de los hallazgos puede diferir tanto dentro de una familia, como entre familias con la misma variante patogénica [5].

\section{Caso clínico}

Paciente masculino adulto joven de 23 años, agricultor y constructor, originario del municipio de Popayán, procedente de la vereda La Rivera, ubicada en zona rural del municipio de Timbío (Cauca, Colombia). Fue captado de forma incidental por uno de los autores, estudiante de Medicina de la Universidad del Cauca, quien notó que todas sus uñas presentaban crecimiento y forma anormal. Una vez el paciente se encontró bajo la supervisión por el área de Genética Clínica del Hospital Universitario San José de Popayán (HUSJ), se procedió a la elaboración de la historia clínica mediante anamnesis y examen físico completos.

Como antecedentes perinatales relató que fue producto de la prime-

Tabla 1. Manifestaciones clínicas asociadas con paquioniquia congénita

Queratodermia plantar con ampolla subyacente

Dolor plantar

Distrofia ungueal hipertrófica

Quistes pilosebáceos y/o esteatocistomas

Leucoqueratosis oral

Queratosis folicular

Hiperhidrosis palmoplantar

Dientes natales o prenatales 
ra gestación, de madre de 53 años (G4P4A1V4), parto vaginal institucional sin complicaciones y sin antecedente de exposición a tóxicos durante la gestación. Sin información de consanguinidad entre los padres. Peso y talla bajos para la edad (la madre no recuerda valores), con desarrollo psicomotor adecuado. La madre del paciente refirió observar alteración en las uñas del paciente desde los primeros días de vida, y la presencia de características similares de afectación de las uñas en algunos parientes, incluyendo madre, hermana, sobrinos e hijos, lo cual mostró tres generaciones posiblemente afectadas por la misma patología, tanto hombres como mujeres, como se observa en la figura 1.

El compromiso de las uñas desde los primeros días de vida se describió inicialmente como una coloración amarilla en la zona proximal de la uña que, de forma paulatina, desarrolló deformidad y crecimiento anormal. Las zonas de quera- todermia plantar aparecieron antes de los 10 años de edad, asociadas a dolor moderado durante la marcha o la actividad física; estas aumentaron de tamaño a lo largo de los años y actualmente el paciente presenta dolor permanente y moderado, de 6/10 en la escala subjetiva del dolor, el cual aumenta después de caminar por largo tiempo, trabajar de pie o después del uso prolongado de zapatos cerrados. Todo esto sumado al síntoma de hiperhidrosis moderada, que favorece la humedad de piel y uñas.

Al examen físico, el paciente se mostró en posición indiferente, colaborador, sin apariencia de enfermedad aguda, retraso mental o alteración neurológica. Con fuerza conservada, marcha normal, medidas antropométricas dentro de los parámetros normales, con relación adecuada y simétrica entre las partes de su cuerpo, y no presentó anormalidades anatómicas o dismorfismos a nivel del rostro ni torso. En cavidad oral se encontró leucoquera-

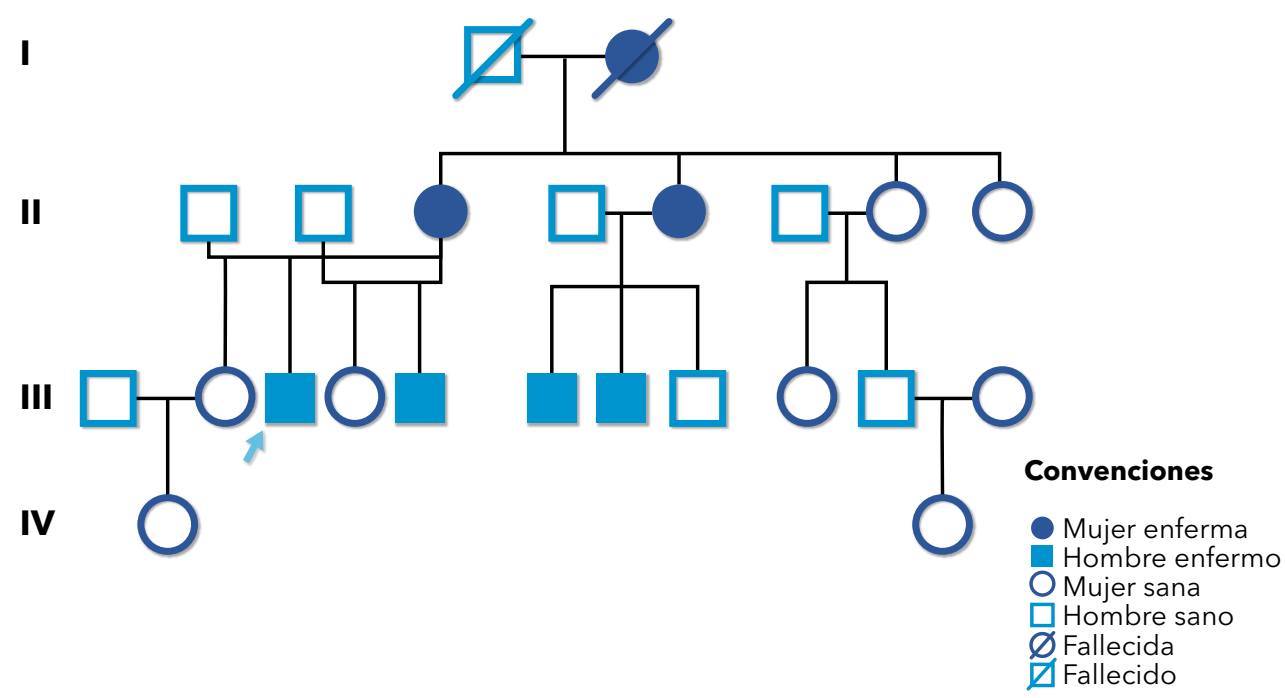

Figura 1. Árbol genealógico en el que se observan tres generaciones afectadas con paquioniquia congénita (PC). 
tosis en bordes laterales posteriores de la lengua, las cuales manifestó no haber notado, ya que no eran dolorosas. Negó haber presentado alteraciones de la masticación, del lenguaje o respiratorias, como apnea obstructiva del sueño. Se observó en todas las uñas de manos y pies una notable distrofia hipertrófica, además de lesiones de queratodermia palmoplantar, algunas ampollosas y dolorosas, y zonas de queratosis folicular en la cara anterior y posterior de los muslos (figura 2).

\section{Discusión}

Como se mencionó, la PC es una enfermedad caracterizada por alteraciones en la queratinización, transmitida por
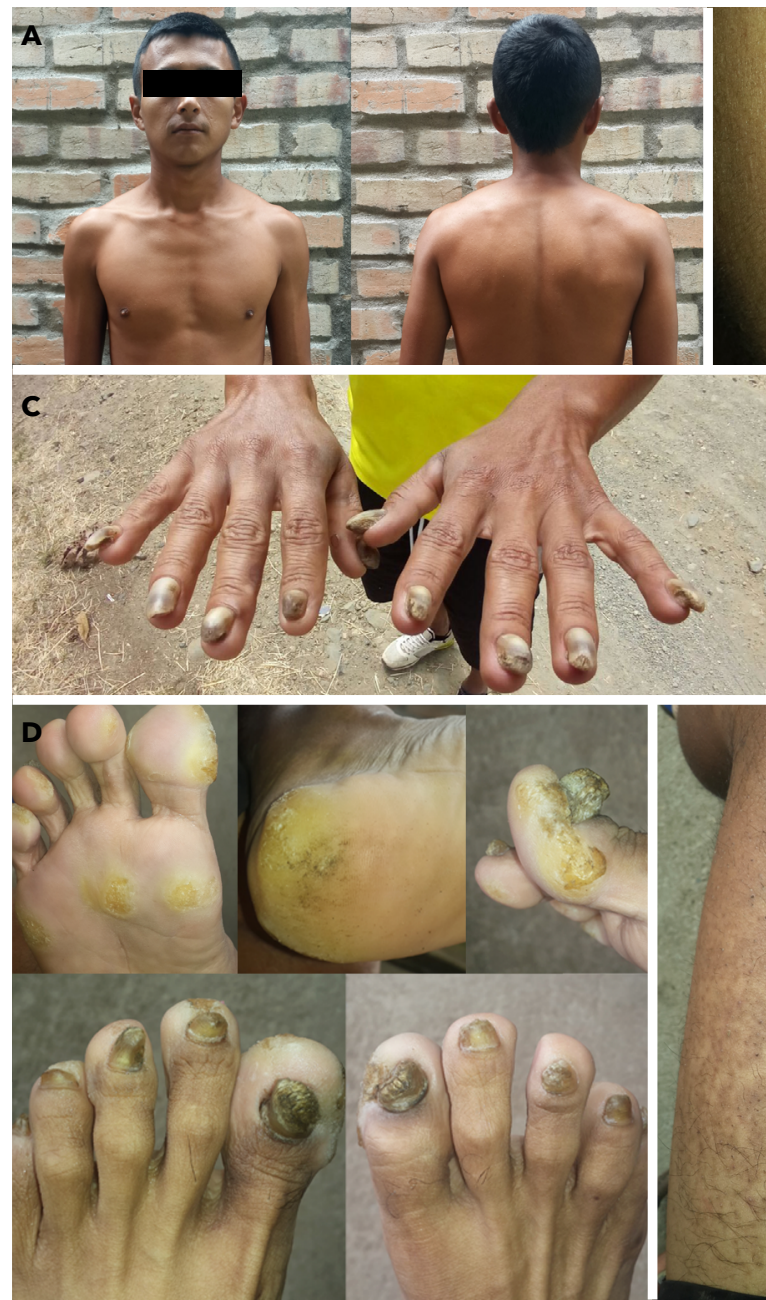
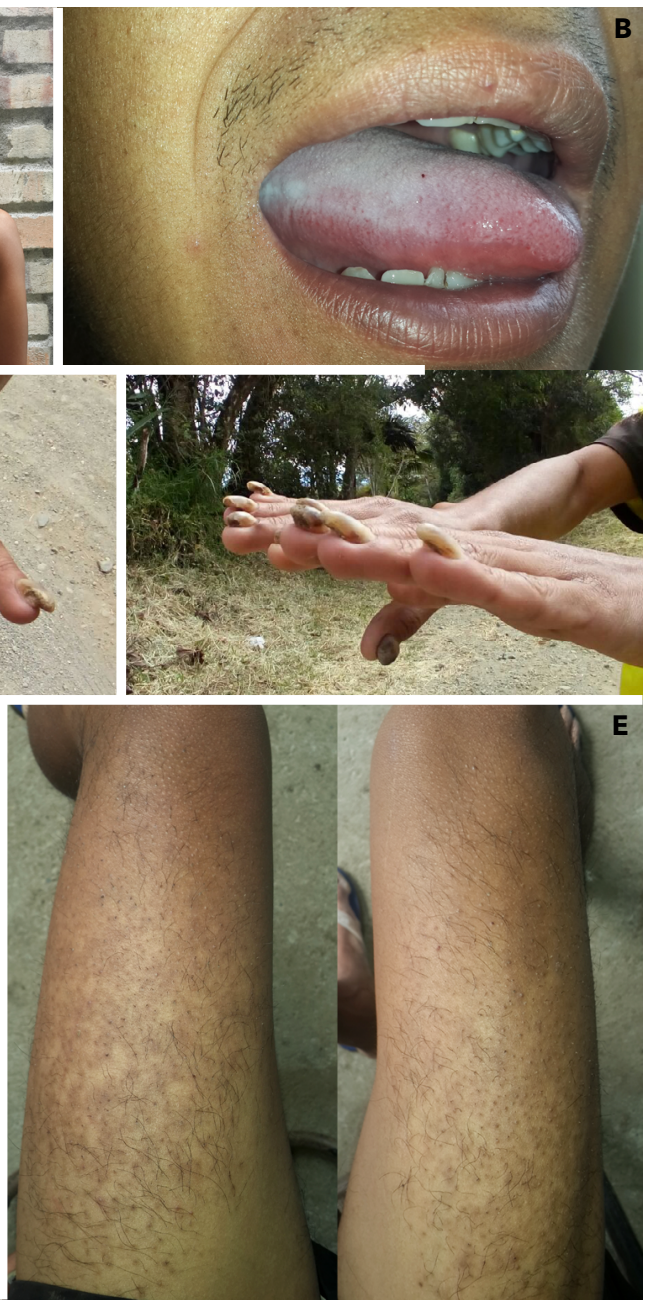

Figura 2. (A) Paciente con desarrollo físico adecuado sin alteraciones en cabello, piel de rostro, ni torso. (B) Leucoqueratosis oral, sin evidencia de queilitis angular. (C) Distrofia ungueal hipertrófica en uñas de las manos. (D) Queratodermia plantar focal y distrofia ungueal hipertrófica en uñas de los pies. (E) Queratosis folicular en muslos. 
herencia autosómica dominante y causada por mutación en uno de los cinco genes que codifican queratinas. El espectro de las mutaciones es amplio, y fenotípicamente la enfermedad se limita al sitio epitelial donde la proteína de queratina mutante se expresa $[3,13-15]$.

La PC afecta a hombres y mujeres por igual. Clínicamente se caracteriza por la tríada de distrofia ungueal, queratodermia palmoplantar y dolor plantar. Es común que las manifestaciones se presenten en la niñez temprana, siendo la distrofia ungueal la manifestación de aparición más temprana en el primer año de vida en la mayoría de los casos, y para los 10 años de edad, ya se encuentran presentes el resto de las manifestaciones clínicas en el $97 \%$ de los afectados con PC confirmada genéticamente $[6,16]$. Otras características clínicas que pueden aparecer son la leucoqueratosis oral, los quistes de diversos tipos, la hiperqueratosis folicular, la hiperhidrosis palmoplantar, disfonía y la presencia de dientes natales $[3,13]$. El principal síntoma que afecta la calidad de vida de los pacientes es el dolor plantar severo [6]. Este dolor está asociado a la formación de ampollas en la profundidad de las áreas de queratodermia palmoplantar, las cuales se desarrollan principalmente sobre los puntos de presión de la superficie de la piel. A menudo el dolor es altamente debilitante [14].

Se han reportado casos de pacientes con dolor de tipo neuropático asociado a la enfermedad. Una posible explicación es que la presencia de dolor crónico produce una sensibilización central que evoca una respuesta de dolor exagerada. Además, el insulto mecánico debido a la formación crónica de ampollas y la queratodermia puede causar un trauma en las terminaciones nerviosas, haciéndolas más susceptibles a las lesiones [17].
Inicialmente, la PC se clasificó de acuerdo con clínica en dos subtipos [5,6]:

- PC tipo 1 (tipo Jadassohn-Lewandowsky), caracterizado principalmente por la leucoqueratosis oral, y causado por la mutaciones en los genes KRT6A o KRT16.

- PC tipo 2 (tipo Jackson-Lawler), caracterizado por presencia de dientes natales y quistes, y causado por las mutaciones en los genes KRT6B o KRT17.

En 2011, el análisis de la información clínica y molecular de más de 250 casos de PC confirmados genéticamente, recopiladas por el IPCRR, mostró una superposición clínica entre estos subtipos. En consecuencia, la nomenclatura se revisó en función del genotipo y de los datos genéticos moleculares dando origen a una nueva clasificación, la cual será descrita a continuación $[5,15]$.

\section{PC-K6a}

Causada por variantes patogénicas en KRT6A. Estos pacientes experimentan queratodermia plantar dolorosa como la característica más relevante. La afección generalmente es evidente al nacer por la presencia de distrofia ungueal en todas las uñas, las cuales pueden estar extremadamente engrosadas o no crecer completamente. Cerca del $100 \%$ de los pacientes experimentan dolor y queratodermia plantar antes de los 10 años de edad. Los niveles de dolor suelen ser de 6 a 9 en una escala de 0 a 10. La leucoqueratosis en la mucosa oral aparece a temprana edad y a menudo se diagnostica erróneamente como aftas. Los lactantes pueden tener problemas de alimentación o succión. La hiperqueratosis folicular es molesta para los niños de hasta 12 años de 
edad aproximadamente, y luego disminuye; ocurre en áreas de fricción como los codos y rodillas [9].

\section{PC-K6b}

Causada por variantes patogénicas en KRT6B. Los pacientes tienen una forma más leve de $P C$, pero experimentan queratodermia plantar dolorosa como característica más desafiante. La condición a menudo no es evidente al nacer, pero se manifiesta antes de los 15 años en el $90 \%$ de los pacientes. Mientras que casi el $100 \%$ tiene algún grado de distrofia en uñas de los pies, menos del $50 \%$ tiene distrofia en uñas de las manos. La leucoqueratosis oral se encuentra solo en un pequeño porcentaje, y generalmente es leve. Los quistes y la hiperqueratosis folicular se informan en muchos de los pacientes, y son leves. Casi el $100 \%$ de los pacientes reportan queratodermia plantar dolorosa. Los niveles de dolor son a menudo de 3 a 5 en una escala de 0 a 10 [9].

\section{PC-K6c}

Causada por variantes patogénicas en KRT6C. Los pacientes afectados tienen la forma más leve de PC, pero presentan queratodermia palmoplantar focal. Sin embargo, debido a que existe información sobre pocos pacientes, no es posible generalizar los hallazgos ni determinar el fenotipo [9].

\section{PC-K16}

Causada por variantes patogénicas en KRT16. Pueden tener uñas extremadamente engrosadas o poca/nula distrofia ungueal. La queratodermia plantar dolorosa es la característica más desafiante. La afección generalmente no es evidente al nacer, pero casi el 100\% tiene fenotipo antes de los 14 años. Algunos pacientes solo presentan queratodermia palmar. Los niveles de dolor a menudo abarcan de 4 a 7 en una escala de 0 a 10. La leucoqueratosis oral, los quistes o la hiperqueratosis folicular se encuentran solo en un pequeño porcentaje de estos pacientes [9].

\section{PC-K17}

Causada por variantes patogénicas en KRT17. Estos pacientes tienen la mayor variación de fenotipos para PC. La condición puede ser evidente al nacer debido a los dientes natales, los cuales son exclusivos de este tipo de PC. Alguna distrofia ungueal también puede estar presente al nacer, pero los cambios en las uñas pueden ser más leves. Casi el $50 \%$ de los pacientes tienen poca o ninguna queratodermia plantar o dolor. Los niveles de dolor pueden variar de 1 a 9 en una escala de 0 a 10. La leucoqueratosis en la mucosa oral rara vez está presente. Se encuentran extensos quistes de esteatocistoma (esteatocistoma múltiple) en casi todos los pacientes; sin embargo, no todos los pacientes con esteatocistoma múltiple tienen mutaciones en el gen KRT17 [9].

El diagnóstico de PC se establece clínicamente con la tríada descrita o mediante la identificación de una variante heterocigótica patogénica en uno de los cinco genes mencionados. Las pruebas genéticas moleculares son el método estándar para confirmar la PC; el análisis de secuencia de cada uno de los genes involucrados puede identificar mutaciones en aproximadamente el 90\% de los pacientes con diagnósticos clínicos previos de PC $[5,18]$. Las pruebas genéticas moleculares pueden incluir análisis seriados de un solo gen, el uso de un panel multigénico o pruebas 
genómicas más exhaustivas. Para individuos que tienen queratodermia palmoplantar focal, el análisis de la secuencia de KRT6C y KRT16 puede considerarse, y para individuos que tienen esteatocistoma múltiple o antecedentes de dientes natales, el análisis de la secuencia de KRT17 [5,10].

El examen histológico, inmunohistológico o por microscopía electrónica de las uñas o la piel no es útil para confirmar el diagnóstico de PC, pero se puede realizar para descartar otros diagnósticos [5].

El presente reporte de caso describe un paciente adulto joven con características fenotípicas particulares, asociadas a alteraciones en la queratinización dadas por queratodermia palmoplantar, queratosis folicular, distrofia ungueal y leucoqueratosis oral, con ausencia de quistes pilosebáceos, esteatocistomas y dientes natales. Además, con antecedentes familiares de hallazgos similares que muestran afectación tanto de hombres como de mujeres, en donde se observa que los individuos afectados proceden de un progenitor también enfermo, lo cual evidencia la presencia de un patrón de herencia autosómica dominante. Este cuadro clínico no ha sido previamente relacionado con un diagnóstico preciso en ninguno de los miembros de la familia.

A partir de estos hallazgos, el paciente es valorado por el grupo de Genética Clínica del HUSJ de Popayán y se establece el diagnóstico netamente clínico de paquioniquia congénita tipo I, también conocida como síndrome de Jadassohn-Lewandowsky. La clasificación desde el punto de vista genético no se pudo realizar, ya que en nuestro medio no se encuentra disponible la prueba molecular, y por lo tanto, no se pudo esclarecer exactamente a qué gen mu- tado estaban asociadas las características clínicas. Sin embargo, gracias a los datos aportados por el IPCRR, se pudo hacer una correlación entre la clínica del paciente y los genes posiblemente implicados.

Desde 2004, el IPCRR realiza la genotipificación como un servicio para las familias inscritas y ha proporcionado una gran cantidad de información sobre las características de la PC y las correlaciones genotipo-fenotipo. Hasta enero de 2020 había recopilado datos clínicos y moleculares de 977 pacientes pertenecientes a 517 familias en 52 países de todo el mundo con PC confirmada genéticamente (figura 3). Estos datos muestran una lista de mutaciones para cada uno de los cinco genes involucrados en PC, y gráficos y esquemas con información genética y clínica relevante, que permite asociar cada gen mutado con determinadas condiciones clínicas y características fenotípicas [9].

Teniendo en cuenta que el paciente presentaba queratodermia plantar dolorosa como principal motivo de consul-

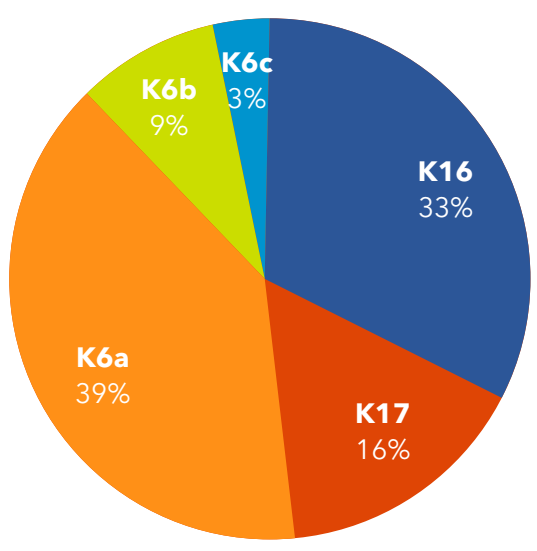

Figura 3. Distribución de los genes implicados en paquioniquia congénita en 977 individuos de 517 familias, confirmados genéticamente [9]. 
ta, la cual catalogó de 6/10 en la escala subjetiva del dolor, esta se encuentra presente en PC-K6a y PC-K16. La distrofia ungueal fue observada por la madre desde los primeros días de vida, lo cual también se describe en las clasificaciones PC-K6a y PC-K16; actualmente se caracteriza por uñas engrosadas en su totalidad, lo cual se correlaciona más con PC-K6a. El hallazgo de leucoqueratosis fue incidental durante el examen físico por parte de los examinadores y no generaba síntomas, por lo cual se pudo definir como una leucoqueratosis oral leve, igualmente descrita en PC-K6b y PC-K16. La hiperqueratosis folicular, presente desde la adolescencia, se asocia también a pacientes con PC-K6b y PCK16. La ausencia de dientes natales y esteatocistomas reducía la posibilidad de que la causa de la PC fuera una variante patogénica mutada del gen KRT17. Con todo lo anterior, se puede deducir que las características clínicas que presentaba el paciente se correlacionaban, en su mayoría, con las que causan las mutaciones de los genes KRT6A o KRT16, las cuales de acuerdo con el IPCRR son las de mayor frecuencia.

Hasta el momento no se conoce ningún tratamiento o cura específica para la PC, por lo cual la terapia generalmente se dirige hacia la mejoría sintomática $[7,13]$. El dolor crónico secundario a la queratodermia plantar con ampollas subyacentes y la hiperhidrosis, es a menudo el aspecto más debilitante de la enfermedad, y se ha reportado, además, la asociación con dolor neuropático en dos terceras partes de los pacientes afectados [19]. Con respecto a su manejo, se publicó en la revista Anesthesia \& Analgesia en el año 2016, un reporte de caso que describe una paciente de 11 años con diagnóstico de PC y síntomas de dolores punzantes, quien presentó mejoría marcada con el uso de gabapentina e inyec- ciones plantares de toxina botulínica, combinadas con asesoramiento psicológico, terapia cognitivo-conductual y fisioterapia [17]. Y más recientemente en 2020, un grupo liderado por Koren y colaboradores, hizo un seguimiento por 4 años a 5 pacientes a quienes se les aplicó toxina botulínica intradérmica plantar, con mejoría significativa en la calidad de vida [20].

Los tratamientos mecánicos como limar, cortar y recortar las uñas y callos son efectivos para reducir los síntomas solo en casos leves de la enfermedad. El tratamiento farmacológico más común son los agentes retinoides, los cuales pueden causar adelgazamiento de la epidermis con ulteriores ampollas dolorosas e infecciones secundarias. Los informes de manejo quirúrgico para la hiperqueratosis son escasos en la literatura. La electrofulguración, el curetaje profundo y la escisión radical con reconstrucción autóloga han tenido un éxito variable, debido a la recurrencia y morbilidad asociada significativa [21].

Para evaluar el valor de la extracción de las uñas en $P C$, se realizó una encuesta a 18 pacientes inscritos en el IPCRR, a quienes se les realizó este procedimiento. Trece recomendarían este método a otras personas con PC, y la razón más común fue la reducción del dolor y la sensibilidad. Estos hallazgos sugieren que la extracción de uñas podría ser beneficiosa y estar siendo infrautilizada. Se necesitan estudios adicionales para establecer qué pacientes con PC pueden ser los más beneficiados con este procedimiento, y qué método o métodos pueden lograr el mejor resultado [22].

El uso de la inyección de un ARN pequeño de interferencia (siRNA) específico para la mutación, se viene estudiando como método para el tratamiento de la PC. Sin embargo, estas inyecciones 
deben aplicarse en la lesión y resultan ser muy dolorosas [23]. Otras opciones de tratamiento bajo investigación para pacientes con PC son la rapamicina, la simvastatina y factores biológicos del factor de necrosis tumoral; estas terapias, aunque brindan esperanza a los pacientes, aún no se aplican de forma rutinaria $[5,7,21]$.

El Consorcio Internacional de Paquioniquia Congénita (IPCC, del inglés, International Pachyonychia Congenita Consortium) es un grupo de médicos y científicos de diversas partes del mundo dedicado al desarrollo de terapias para esta enfermedad. En su último simposio de 2019 resaltan los avances en las terapias dirigidas a la respuesta inflamatoria que participa en el desarrollo de los callos, y a la supresión o modificación de la expresión de los genes, mediante el uso de ácidos nucleicos, entre otras terapias. Estas alternativas terapéuticas apuntan todas a mitigar el dolor debilitante en los pacientes con PC [24].

\section{Conclusiones}

La PC es una rara enfermedad genética con características fenotípicas determinadas por el gen que se encuentra mutado. Se presentó el caso de un hombre joven con manifestaciones clínicas claras de la enfermedad e historia familiar similar, lo cual permitió establecer el diagnóstico clínico de paquioniquia congénita tipo I o síndrome de Jadassohn-Lewandowsky.

Actualmente no se puede catalogar al paciente dentro de una de las clasificaciones genéticas, ya que aún no se dispone en el medio de la prueba genética molecular que lo permita. Se conoce que la gravedad de los hallazgos clínicos puede diferir dentro de una misma familia afectada con la misma variante patogénica, y que la ausencia o presencia de ciertas características, así como la edad de inicio, también varía según el gen mutado. De acuerdo con la correlación entre los hallazgos clínicos y los genéticos realizados por el IPCRR, se estima que la mutación más probable en este paciente estaría en los genes KRT6A o KRT16.

Con respecto al tratamiento, es importante la aplicación de medidas conservadoras como reducir la fricción, el trauma y la hidratación de la epidermis, así como buscar alternativas de tratamiento para la mejoría del dolor y apariencia, relevantes en su vida social y laboral. Eventualmente, será importante que el paciente y su familia tengan la oportunidad de acceder a estudios genéticos que permitan identificar la variante patogénica del gen mutado y recibir los tratamientos adecuados.

\section{Referencias}

1. Moger G, Shashikanth M, Chandrashekar K, Kurein S. Pachyonychia congenita tarda: A rare case report. Contemp Clin Dent 2013;4:409-411. https://doi.org/10.4103/0976-237x.118374.

2. Scully C, Langdon J, Evans J. Marathon of eponyms: 10 Jadassohn-Lewandowsky syndrome (Pachyonychia congenita). Oral Dis 2010;16:310-311. https://doi.org/10.1111/ j.1601-0825.2009.01542.x.

3. Wilson NJ, O'Toole EA, Milstone LM, Hansen CD, Shepherd AA, Al-Asadi E, et al. The molecular genetic analysis of the expanding pachyonychia congenita case collection. $\mathrm{Br}$ J Dermatol 2014;171:343-355. https://doi. org/10.1111/bjd.12958.

4. Steele L, O'Toole EA. Pachyonychia congenita, a paradigm for rare skin disorders. $\mathrm{Br}$ J Dermatol 2020;182:521-522. https://doi. org/10.1111/bjd.18817.

5. Smith FJ, Hansen D, Hull PR, Kaspar RL, McLean I, O'Toole E, et al. Pachyonychia con- 
genita. GeneReviews ${ }^{\circledR}$. Seattle (WA): University of Washington; 2017. Acceso 4 de enero de 2020. Disponible en https://www.ncbi.nlm.nih. gov/books/NBK1280/.

6. Samuelov L, Smith FJD, Hansen CD, Sprecher E. Revisiting pachyonychia congenita: a case-cohort study of 815 patients. Br J Dermatol 2020;182:738-746. https://doi.org/10.1111/ bjd.18794.

7. Goldberg I, Fruchter D, Meilick A, Schwartz ME, Sprecher E. Best treatment practices for pachyonychia congenita. J Eur Acad Dermatol Venereol 2014;28:279-285. https://doi. org/10.1111/jdv.12098.

8. García-Izquierdo $M$, Urquiaga $T$, De los Ríos P, Urquiaga J. Paquioniquia congénita: a propósito de un caso. Dermatol Peru 2009; 19:332-338.

9. Schwartz J. Pachyonychia Congenita Project. PC data. Halladay, Utah: Pachyonychia Congenita Project; 2020. Acceso 15 de enero de 2020. Disponible en https://www.pachyonychia.org/ pc-data/.

10. Shah S, Boen M, Kenner-Bell B, Schwartz M, Rademaker A, Paller AS. Pachyonychia congenita in pediatric patients: Natural history, features, and impact. JAMA Dermatology 2014;150:146-153. https://doi.org/10.1001/ jamadermatol.2013.6448.

11. Kishan-Kumar $Y$, Keerthi S. Pachyonychia congenita affecting nails only: A sporadic case or novel mutation of an uncommon genodermatoses. Int J Health Allied Sci 2017;6:191-193. https://doi.org/10.4103/ijhas.IJHAS_158_16.

12. Cárdenas ML, Balcázar LF, Vargas N. Paquioniquia congénita: reporte de un caso. Rev Asoc Colomb Dermatol Cir Dermatol 2019;17:242-244.

13. Brill S, Sprecher E, Smith FJD, Geva N, Gruener $\mathbf{H}, \mathbf{N a h m a n - A v e r b u c h ~} \mathbf{H}$, et al. Chronic pain in pachyonychia congenita: evidence for neuropathic origin. Br J Dermatol 2018;179:154162. https://doi.org/10.1111/bjd.16217.

14. McLean WH, Hansen CD, Eliason MJ, Smith FJ. The phenotypic and molecular genetic features of pachyonychia congenita. J Invest Dermatol 2011;131:1015-1017. https://doi. org/10.1038/jid.2011.59.
15. Chiriac A, Rusu C, Murgu A, Chiriac AE, Wilson NJ, Smith FJD. First report of pachyonychia congenita type PC-K6a in the Romanian population. Maedica 2017;12:123-126.

16. Eliason MJ, Leachman SA, Feng BJ, Schwartz ME, Hansen CD. A review of the clinical phenotype of 254 patients with genetically confirmed pachyonychia congenita. J Am Acad Dermatol 2012;67:680-686. https:// doi.org/10.1016/j.jaad.2011.12.009.

17. Tariq S, Schmitz ML, Kanjia MK. Chronic foot pain due to pachyonychia congenita in a pediatric patient: A successful management strategy. A A Case Rep 2016;6:305-307. https://doi. org/10.1213/xaa.0000000000000301.

18. dos Santos VM, Loures TP, Rego JDB, Teixeira CA, de Carvalho KD, Nascimento ALO. A case with pachyonychia congenita and B-cell lymphoma. Acta Med Iran 2014;52:578-581.

19. Thomas BR, Sahota A. Pachyonychia congenita and botulinum toxin. Br J Dermatol 2020;182:531532. https://doi.org/10.1111/bjd.18784.

20. Koren A, Sprecher E, Reider E, Artzi O. A treatment protocol for botulinum toxin injections in the treatment of pachyonychia congenita-associated keratoderma. Br J Dermatol 2020;182:671677. https://doi.org/10.1111/bjd.18169.

21. Mandelbaum M, Chao JW, Rogers GF. Pachyonychia congenita in a toddler. Plast ReconstrSurg Glob Open2017;5:e1325.https:// doi.org/10.1097/GOX.0000000000001325.

22. DeKlotz CMC, Schwartz ME, Milstone LM. Nail removal in pachyonychia congenita: Patient-reported survey outcomes. J Am Acad Dermatol 2017;76:990-992. https://doi. org/10.1016/j.jaad.2016.08.060.

23. Funk T, Hansen CD, Paller A, O'Toole EA. Update on pachyonychia congenita research. Br J Dermatol 2020;182:788-789. https://doi. org/10.1111/bjd.18630.

24. Funk T, Hansen C, Paller A, O'Toole E. Report of the 16th Annual International Pachyonychia Congenita Consortium (IPCC) Symposium. IPCC Newsletter. Halladay, Utah: Pachyonychia Congenita Projec; 2019 Vol 16. Acceso 20 de febrero de 2020. Disponible en https://www.pachyonychia.org/wp-content/uploads/2019/10/ FunkT2019.pdf. 